\title{
The Environmental Fate of Natural and Synthetic Oestrogens; Comparison between Prediction Tools and Experimental Values
}

\author{
E. A. Aziz, W. A. Wan Omar, and N. A. Zainodin
}

\begin{abstract}
The increasing demand for clean water leads to reuse practices such as the uses of sewage effluent in crops irrigation. However, the extent to which the effluent is safe to be used as irrigation water remains uncertain. Natural and synthetic oestrogens are ubiquitous in effluents and they are present in the final effluents for the vast majority of waste water treatment plants. Thus for this study, it was necessary to determine their sorption to soils in order to assess the possible human exposure from irrigation water. EPISUITE uses a prediction model whereby the inherent chemical and physical properties are used to determine the partition coefficients for each environmental compartment. However, this is a default model which can be made more accurate by experimentally measuring these partition coefficients. The $K_{\mathrm{ow}}, K_{\mathrm{oc}}$ and $K_{\mathrm{d}}$ of these compounds were measured and computed to determine environmental fate. The experimental model was later compared to the default model. It can be concluded that by inputting the experimental values, the model changes remarkably and has given absolute values to the ambient conditions.
\end{abstract}

Index Terms-Natural and synthetic oestrogens, EPISUITE, octanol-water partition coefficient $\left(K_{\text {ow }}\right)$, soil-water partition coefficient $\left(K_{\mathrm{d}}\right)$, environmental distribution.

\section{INTRODUCTION}

The application of prediction tools based on computational modelling to assess the environmental fate of any environmental pollutant has been widely accepted and used in scientific communities and regulators. The most popular tool and freely available to be used is the Estimation Program Interface (EPISUITE). This software was developed by the Environmental Protection Agency (EPA) (Office of Pollution Prevention and Toxic Substances) and Syracuse Research Corporation (SRC). The main purpose of this software is to support the EPA's decision making regarding the toxicity, environmental fate and transport of new chemicals.

The EPISUITE software basically consists of two modules where the first module is Physical-chemical Property Estimation Routine (PERs), which are working to predict important physical chemical properties such as water

Manuscript received May 6, 2014; revised October 14, 2014. This work was supported by Ministry of Higher Education (MOHE) under Grant RDU110356.

The authors are with University Malaysia Pahang, Malaysia (email: nedadib79@gmail.com,_nurulainzainordin@gmail.com, wanatikah638@yahoo.com). solubility $\left(S_{\mathrm{w}}\right)$, vapour pressure, octanol-water partition coefficient $\left(K_{\mathrm{ow}}\right)$ and reactivity e.g biodegradation, atmospheric oxidation. By working together with the second module, Environmental Fate Models (EFMs), this software is able to project a chemical's environmental fate and transport in environmental compartments.

Although this kind of software is helpful to assess the environmental fate of any new emerging contaminants, experimental assessment still needs to be carried out. The model does not consider such ambient conditions as temperature, $\mathrm{pH}$, soil type etc. Therefore experimentation and reporting is essential in order to ensure a realistic model of the environment under consideration is obtained as opposed to the default model given by the software. In real experimentation, there are many factors that affect the results. The ambiguity problem between experimental and default values has led to the creation of EPISUITE whereby inputting experimental values attempts to move to a more realistic model true to the environment under consideration.

In this work, two essential parameters $\left(K_{\mathrm{ow}}\right.$ and $\left.K_{\mathrm{oc}}\right)$ needed by the EPISUITE to model the environmental fate of oestrogens were obtained experimentally. The comparison between the experimental and default values were then assessed and discussed.

\section{MATERIALS AND METHODS}

\section{A. Soil}

Three individual soils were manufactured in the laboratory by mixing quantities of sand, silt, clay and humus as seen in Table I. These three types of soil were named as I, II and III. All the soils were prepared in accordance to the BS 3882:1994 [1] and all the individual material sizes were in accordance to the BS 1377-1:1990 [2].

\begin{tabular}{|c|c|c|c|c|c|c|}
\hline Soil & $\begin{array}{l}\text { Sand } \\
(\%)\end{array}$ & $\begin{array}{l}\text { Silt } \\
(\%)\end{array}$ & $\begin{array}{l}\text { Clay } \\
(\%)\end{array}$ & $\begin{array}{l}\text { Humus } \\
(\%)\end{array}$ & $\begin{array}{l}\text { OM } \\
(\%)\end{array}$ & $\begin{array}{l}\text { OC } \\
(\%)\end{array}$ \\
\hline I & 75 & 10 & 5 & 10 & 8.90 & 5.16 \\
\hline II & 80 & 10 & 5 & 5 & 4.92 & 2.85 \\
\hline III & 84 & 10 & 5 & 1 & 1.62 & 0.94 \\
\hline
\end{tabular}

\section{B. Chemicals}

The oestrogens used in all experiments were Oestrone (99\%, Acros Organic), 17 $\beta$-estradiol (> 98\%, Sigma Aldrich) and $17 \alpha$-ethnyloestradiol (> 98\%, Sigma Aldrich). The chemical structures of these compounds are shown in Fig. 1 and their major physicochemical properties are summarized in Table II. 


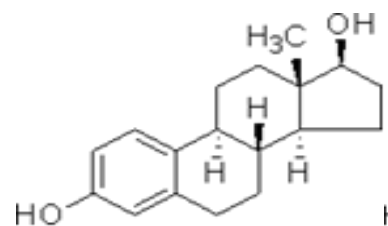

(a)

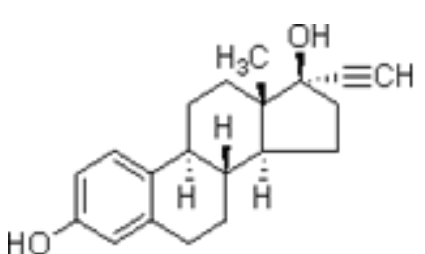

(c)

Fig. 1. Chemical structures of oestrogens. (a) 17ß-oestradiol (E2), (b) Oestrone (E1), (c) 17 $\alpha$-ethnyloestradiol (EE2).

TABLE II: PHYSICAL-CHEMICAL CHARACTERISTICS OF OESTROGENS

\begin{tabular}{|c|c|c|c|}
\hline & $\begin{array}{l}\text { 17ק-Oestradiol } \\
\text { (E2) }\end{array}$ & $\begin{array}{l}\text { Oestrone } \\
\text { (E1) }\end{array}$ & $\begin{array}{c}\text { 17 } \alpha \text {-ethnyloestradiol } \\
\text { (EE2) }\end{array}$ \\
\hline $\begin{array}{l}\text { Molecular } \\
\text { formula }\end{array}$ & $\mathrm{C}_{18} \mathrm{H}_{24} \mathrm{O}_{2}$ & $\mathrm{C}_{18} \mathrm{H}_{22} \mathrm{O}_{2}$ & $\mathrm{C}_{20} \mathrm{H}_{24} \mathrm{O}_{2}$ \\
\hline $\begin{array}{l}\text { Molecular } \\
\text { weight } \\
\left(\text { gmol }^{-1}\right)\end{array}$ & 272.3 & 270.4 & 296.4 \\
\hline $\begin{array}{l}\text { Vapour } \\
\text { pressure } \\
(\mathrm{Pa})\end{array}$ & $3 \times 10^{-8}$ & $3 \times 10^{-8}$ & $6 \times 10^{-9}$ \\
\hline $\begin{array}{l}\text { Aqueous } \\
\text { solubility } \\
\left(\mathrm{mgl}^{-1}\right)^{\mathbf{a}}\end{array}$ & 81.97 & 146.8 & 116.4 \\
\hline $\begin{array}{l}\text { Aqueous } \\
\text { solubility } \\
\text { at } 2^{\circ} \mathrm{C} \\
\left(\mathrm{mgl}^{-1}\right)^{\mathbf{b}} \\
\end{array}$ & $3.1 \pm 0.02$ & $2.1 \pm 0.03$ & $3.1 \pm 0.03$ \\
\hline $\log K_{\text {ow }}^{c}$ & 3.94 & 3.43 & 4.12 \\
\hline
\end{tabular}

a. WSKOWWIN (EPISUITE)

b. From [3]

c. KOWWIN (EPISUITE)

\section{Methodology}

All individual stock solutions of chemicals (E1, E2 and EE2) at concentrations $1000 \mathrm{mgl}^{-1}$ were prepared by dissolving appropriate amounts of the chemicals in high performance liquid chromatography (HPLC) grade methanol. Serial dilutions of the stock solution using nanopure water were carried out to prepare working solutions in the range $0.1-0.5 \mathrm{mgl}^{-1}$. The solutions were analysed on a reverse phase high performance liquid chromatograph (Dionex UltiMate 3000 fitted with 20ul loop, with Dionex Variable Wavelength Detector set at $\lambda 220 \mathrm{~nm}$, Analytical Column-Allure Biphenyl $5 \mu \mathrm{m} 60 \AA 150$ $\times 4.6 \mathrm{~mm}$ ). The mobile phase used was a mixture of HPLCgrade acetonitrile and nanopure water at ratios of 60:40 $(\mathrm{v} / \mathrm{v})$.

\section{A. Determination of Octanol-Water Partition Coefficient $\left(K_{\text {ow }}\right)$}

The $K_{\mathrm{ow}}$ was measured by Reverse Phase-HPLC method [4]. The method is based on the fact that substances will partition between the polar mobile phase and non-polar stationary phase, with high $K_{\text {ow }}$ values eluting later on a reverse phase column than substance with lower $K_{\text {ow }}$ values. The $K_{\text {ow }}$ was determined from the analysis of retention time obtained. Six reference substances (Napthalene, 99\% Acros Organic; Anthracene, 99\% Sigma Aldrich; Fluoranthene,
99\% Sigma Aldrich; Crysene, 95\% Sigma Aldrich; Benzo (a) pyrene, 97\% Sigma Aldrich and Benzoic acid, 99.5\% Sigma Aldrich) were selected based on having similar structures to the test compounds as well as encompassing the required range of $\log K_{\mathrm{ow}}$ values. Two stock solutions were prepared in HPLC-grade methanol 1. A mixed of 1 $\mathrm{mgl}^{-1}$ of reference substances and 2. A mixed of $1 \mathrm{mgl}^{-1}$ of oestrogens standard. The wavelength used for reference substances was $254 \mathrm{~nm}$ while for oestrogens it was $220 \mathrm{~nm}$. The dead time, $\mathrm{t}_{0}$ was measured by using organic substances Thiourea (99\% Sigma Aldrich). The $\log K_{\mathrm{ow}}$ of the reference substances were plotted against $\log$ capacity factor $(\log k)$ and from the linear equation the $\log K_{\mathrm{ow}}$ of the oestrogens was calculated.

\section{B. Determination of Sorption Coefficients $\left(K_{d}\right)$ and Organic Carbon Normalised Sorption Coefficient $\left(K_{o c}\right)$}

The sorption coefficients $\left(K_{\mathrm{d}}\right)$ of oestrogens on soils were determined by using a batch equilibrium method in accordance to ASTM standard E1195-01 [1]. For each batch equilibrium experiment, in duplicate, oestrogen solution (0$0.5 \mathrm{mgl}^{-1}$ ) was added to $0.25 \mathrm{~g}$ of air-dry soil in $25 \mathrm{~mL}$ Teflon centrifuge tubes. All tubes were continuously mixed horizontally on a rotary shaker set at $300 \mathrm{~min}^{-1}$ at $20 \pm 1^{\circ} \mathrm{C}$ and in the dark. Shaking times were 24 hours. In all experiments, tubes containing no sorbent were run simultaneously to assess loss of solutes to tubes during sorption experiment. At the completion of experiments, soil slurries were centrifuged at $4000 \mathrm{rpm}$ for 20 minutes. After centrifugation, the supernatants were further filtered through Whatman glass fiber filter $(\mathrm{GF} / \mathrm{C})$. The filtrates were then analysed by analytical techniques mentioned. $K_{\mathrm{oc}}$ the organic carbon partition coefficient, was calculated from the obtained $K_{\mathrm{d}}$ value as presented in equation (1) [5], [6]. Therefore, the experimental $K_{\mathrm{d}}$ values were re-calculated to $K_{\mathrm{oc}}$ values. Then, the results were compared to the $K_{\mathrm{oc}}$ value from computational program (default values).

$$
K_{\mathrm{oc}}=K_{\mathrm{d}} / \% \mathrm{OC} \times 100
$$

\section{EPISUITE}

The EPISUITE used in this work was freely obtained from the United State-Environmental Protection Agency (US-EPA) website (http://www.epa.gov/opptintr/exposure/pubs/episuitedl.htm).

\section{RESUlTS AND DisCUSSION}

\section{A. Determination of $\log K_{o w}$}

The octanol-water partition coefficient $\left(\log K_{\text {ow }}\right)$ of oestrogens was obtained by using equation (2).

$$
\log K_{\mathrm{ow}}=a+b \times \log k
$$

where, $a, b=$ linear regression coefficients.

$$
k=\left(t_{R}-t_{0}\right) / t_{0}
$$

where, $t_{R}=$ retention time of the test substance

$$
t_{0}=\text { dead time }
$$




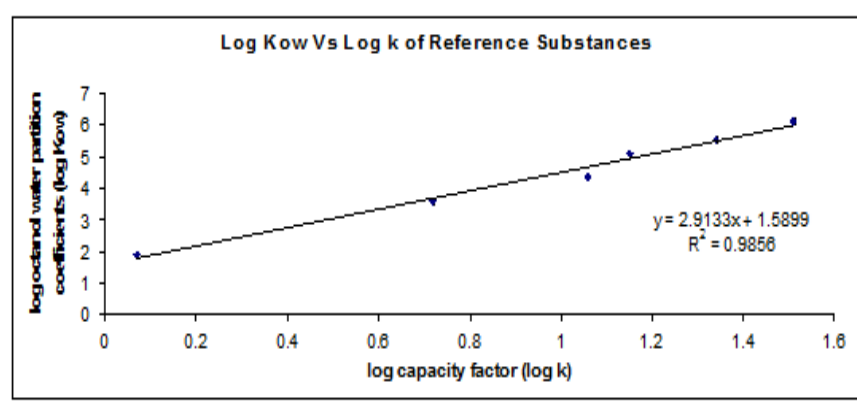

Fig. 2. Correlation graph between $\log K_{\text {ow }}$ and $\log$ capacity factor $(\log k)$ of reference substances.

From this experiment, the reference materials showed a linear correlation $(y=2.9133 x+1.5899$ with the coefficient correlation $\left.r^{2}>0.95\right)$ as shown in Fig. 2. Thus, it was suitable to measure $K_{\text {ow }}$ of the three test oestrogens. As in Table III, the $K_{\text {ow }}$ values of these oestrogens were found to be lower than the default values predicted by the EPISUITE (KOWWIN-EPISUITE). The ability of EPISUITE to accurately model physical-chemical properties depends on several factors. The most crucial factor is the chemical's class and whether the chemical's properties fall within the range of the chemical training data set. Historically, the EPISUITE was developed to model the fate and transport behaviour of non-polar organic chemicals, thus all the training data sets were within this class of chemicals. However, due to the presence of functional group such as hydroxyl $(-\mathrm{OH})$ etc in all oestrogens, they were not considered as non-polar organic chemicals, therefore they did not fall within the range of the chemical training data set of EPISUITE. Previously, it has been reported that oestrogens are classified as moderate non-polar to non-polar organic chemicals. However, polar or non-polar is only a relative term. In addition it is difficult to identify the hydrophobicity of the oestrogens as all the oestrogens used in this work have similar structures, however attainment of experimental $\log K_{\text {ow }}$ values is essential as the $\log K_{\text {ow }}$ values are the key parameters governing the environmental fate of organic chemicals especially in the sorption mechanism.

TABLE III: EXPERIMENTAL LOG $K_{\text {OW }}$ VALUES OF OESTROGENS

\begin{tabular}{|c|c|c|c|c|}
\hline Compound & Retention Time(rt) & Logrt & $\begin{array}{l}\log K_{\text {ow }} \\
(y=2.9133 x+1.5899)\end{array}$ & Log $K_{\text {ow }}($ EPISUITE $)$ \\
\hline 17ß-Oestradiol (E2) & 4.28 & 0.63 & 2.34 & 3.94 \\
\hline 17-ethnyloestradiol (EE2) & 5.05 & 0.82 & 2.67 & 4.00 \\
\hline Oestrone (E1) & 6.58 & 0.70 & 3.13 & 3.43 \\
\hline
\end{tabular}

Basically, according to the principal of RP-HPLC, the substance with the higher $\log K_{\mathrm{ow}}$ value elutes later on the reverse phase column than a substance with lower $\log K_{\text {ow }}$ value. The experimental values obtained however showed a contradiction from the values predicted by the EPISUITE. The elution order gained from the experiment did not match with the hydrophobicity order of the default model. The contradiction is believed to be contributed by the mechanism involved in the analytical column and similar problem was encountered and has been reported by a previous researcher [6].

\section{B. Determination of Sorption Coefficients $\left(K_{d}\right)$ and} Organic Carbon Normalised Sorption Coefficient $\left(K_{o c}\right)$

From this experiment, the soil sorption $\left(K_{\mathrm{d}}\right)$ of all test oestrogens exhibited good correlation to the organic carbon content with the coefficient correlations $\left(r^{2}\right)$ ranging between 0.96-0.99. Soil with greater organic carbon content sorbed more oestrogens than soils with lesser organic carbon content. Among the three oestrogens, 17ß-oestradiol (E2) showed the greatest sorption coefficient in all soils while Oestrone (E1) showed the least ability for partitioning to the organic portion of the soils. From this result, the sorption order obtained $(E 2>E E 2>E 1)$ didn't follow the hydrophobicity order $(\mathrm{E} 1>\mathrm{EE} 2>\mathrm{E} 2)$ determined by method explained in Section III.

By inputting the $K_{\mathrm{d}}$ values of all oestrogens in equation 1 , the soil sorption normalized to organic carbon $\left(K_{\mathrm{oc}}\right)$ of all oestrogens were recalculated as shown in Table IV. After recalculating the $\log K_{\mathrm{oc}}$ values, all oestrogens were classified as moderate to strong compounds bound to soils and unlikely to leach into the soil profile.

From the $K_{\mathrm{oc}}$ values input into the EPISUITE along with the experimental $K_{\text {ow }}$ values, the fugacity model changes and has given the absolute distribution percentage of each oestrogen in the environmental compartment at the ambient conditions. The comparison of distribution in the environmental compartments of each oestrogen between default and experiments is shown in Table V.

A significance change can be seen clearly in sediments, where by inputting the recalculated $K_{\mathrm{oc}}$ values the mass amount percentage of all oestrogens were 4-15 times lower than the default.

TABLE IV: FREUNDLICH ADSORPTION ISOTHERM PARAMETERS AS WELL AS THE $K_{\text {OC }}$ VALUES FOR NATURAL OESTROGEN AND SYNTHETIC OESTROGEN IN SOILS

\begin{tabular}{|c|c|c|c|c|c|}
\hline Soil & & $K_{\mathrm{d}}\left(\mathrm{Lkg}^{-1}\right)$ & $r^{2}$ & $K_{\text {oc }}(\exp )$ & $\begin{array}{l}K_{\text {oc }} \\
(\text { PC KOCWIN) }\end{array}$ \\
\hline I & \multirow[t]{3}{*}{ (E2) } & 175.3 & 0.9808 & 3397.3 & \multirow{3}{*}{16000} \\
\hline II & & 90.4 & 0.9948 & 3171.9 & \\
\hline III & & 24.0 & 0.9782 & 2553.2 & \\
\hline I & \multirow[t]{3}{*}{ (EE2) } & 139.3 & 0.9537 & 2699.6 & \multirow{3}{*}{30000} \\
\hline II & & 48.6 & 0.9719 & 1705.3 & \\
\hline III & & 16.9 & 0.9711 & 1797.9 & \\
\hline I & \multirow[t]{3}{*}{ (E1) } & 154.4 & 0.9856 & 2992.2 & \multirow{3}{*}{47700} \\
\hline II & & 76.4 & 0.9891 & 2680.7 & \\
\hline III & & 23.4 & 0.9718 & 2489.4 & \\
\hline
\end{tabular}

However, for the rest of environmental compartments as such as air, water and soil, the mass amount percentage of all oestrogens by inputting the recalculated $K_{\text {oc }}$ values were noticeably higher than default. These results confirm that the distribution capability of all oestrogens in environmental compartments was dependent not only on its physicalchemical structure, but also on the characteristics of the medium such as organic carbon contents as can be seen by the changes of the experimental values in each compartments. The values of the three samples (TP I, TP II and TP III) were not remarkably different compared to each other in every environmental compartment as the organic 
carbon percentage in all soil samples were in the range of 1$5 \%$. It is believed that the soil samples with a higher range of organic carbon content than the soils used in this work would given a better indication of the influence of organic carbon.

However, the organic carbon or the organic matter percentage in all soil samples used in this work was in a typical range of soils (unless peat or forest soil which would have much higher organic matter contents [5]. By inputting the experimental values of $\log \mathrm{K}_{\mathrm{ow}}$ and the recalculated $\mathrm{K}_{\mathrm{oc}}$ values of each oestrogens in all soils, the persistence time calculated were lower than predicted by default. Of all the oestrogens, 17 $\alpha$-ethnyloestradiol (EE2) has shown the greatest recalcitrance in all soils for both experimental and default values. For the experiments, it was then followed by $17 \beta$-oestradiol (E2) and Oestrone (E1), while by using the default the order was reversed.

TABLE V: THE DISTRIBUTIONS OF NATURAL AND SYNTHETIC OESTROGENS IN ENVIRONMENTAL COMPARTMENTS

\begin{tabular}{|c|c|c|c|c|c|}
\hline \multirow{3}{*}{$\begin{array}{l}\text { Environment } \\
\text { al } \\
\text { Compartment }\end{array}$} & \multicolumn{5}{|c|}{$\begin{array}{c}\text { Mass Amount (\%) } \\
\text { (Level III Fugacity Models) }\end{array}$} \\
\hline & \multicolumn{2}{|c|}{ Default } & \multicolumn{3}{|c|}{ Experimental } \\
\hline & \multicolumn{2}{|c|}{ (EPI-Suite $^{\mathrm{TM}}$ ) } & $\mathbf{I}$ & II & III \\
\hline \multicolumn{6}{|c|}{ 17ß-oestradiol (E2) } \\
\hline Air & $2.45 \times 10^{-4}$ & \multicolumn{2}{|c|}{$2.64 \times 10^{-4}$} & $2.64 \times 10^{-4}$ & $2.65 \times 10^{-4}$ \\
\hline Water & 9.76 & \multicolumn{2}{|c|}{11.1} & 11.1 & 11.2 \\
\hline Soil & 81.2 & \multicolumn{2}{|c|}{86.8} & 86.9 & 87.1 \\
\hline Sediment & 9.04 & \multicolumn{2}{|c|}{2.16} & 2.02 & 1.63 \\
\hline $\begin{array}{l}\text { Persistence } \\
\text { Time }\end{array}$ & $\begin{array}{l}84 \\
\text { (days) }\end{array}$ & \multicolumn{2}{|c|}{$\begin{array}{l}78.3 \\
\text { (days) }\end{array}$} & $\begin{array}{l}77.9 \\
\text { (days) }\end{array}$ & $\begin{array}{l}77.5 \\
\text { (days) }\end{array}$ \\
\hline \multicolumn{6}{|c|}{ Oestrone (E1) } \\
\hline Air & $2.33 \times 10^{-3}$ & \multicolumn{2}{|c|}{$2.69 \times 10^{-3}$} & $2.71 \times 10^{-3}$ & $2.71 \times 10^{-3}$ \\
\hline Water & 8.89 & \multicolumn{2}{|c|}{11.4} & 11.6 & 11.6 \\
\hline Soil & 76.0 & \multicolumn{2}{|c|}{86.9} & 87.3 & 87.2 \\
\hline Sediment & 15.1 & \multicolumn{2}{|c|}{1.75} & 1.12 & 1.18 \\
\hline $\begin{array}{l}\text { Persistence } \\
\text { Time }\end{array}$ & 88 (days) & \multicolumn{2}{|c|}{\begin{tabular}{|l|}
76.3 \\
(days)
\end{tabular}} & $\begin{array}{l}75.4 \\
\text { (days) }\end{array}$ & $\begin{array}{l}75.4 \\
\text { (days) }\end{array}$ \\
\hline \multicolumn{6}{|c|}{ 17a-ethnyloestradiol (EE2) } \\
\hline Air & $5.23 \times 10^{-4}$ & \multicolumn{2}{|c|}{$6.48 \times 10^{-4}$} & $6.5 \times 10^{-4}$ & $6.51 \times 10^{-4}$ \\
\hline Water & 5.92 & \multicolumn{2}{|c|}{8.72} & 8.78 & 8.82 \\
\hline Soil & 73.2 & \multicolumn{2}{|c|}{89.4} & 89.5 & 89.6 \\
\hline Sediment & 20.9 & \multicolumn{2}{|c|}{1.87} & 1.67 & 1.55 \\
\hline $\begin{array}{l}\text { Persistence } \\
\text { Time }\end{array}$ & $\begin{array}{l}148 \\
(\text { days })\end{array}$ & \multicolumn{2}{|c|}{$\begin{array}{l}119.6 \\
\text { (days) }\end{array}$} & $\begin{array}{l}119.6 \\
\text { (days) }\end{array}$ & $\begin{array}{l}119.2 \\
\text { (days) }\end{array}$ \\
\hline
\end{tabular}

The prediction persistency of all oestrogens based on the experimental value were less than the default however both of the persistency range of all oestrogens show that these compounds are considered as less stable than other organic pollutants e.g. polyaromatic hydrocarbons (PAHs).

\section{CONCLUSIONS}

Although the prediction tool is available, the experimental value is essential to give an accurate assessment on the environmental fate prediction. This study has revealed that modeling cannot totally replace experimentation for environmental fate prediction.

\section{REFERENCE}

[1] Classification of Topsoil, British Standard BS 3882:1994.

[2] Methods of test for soils for civil engineering purposes - Part 1: General requirements and sample preparation, British Standard BS 1377-1:1990.

[3] H. E. Keenan, "The development of a SPE-HPLC method to analysis to assess the environmental fate of natural and synthetic oestrogens," Ph.D. Dissertation, Dept. Civil. Eng., Strathclyde Univ., Glasgow, United Kingdom, 2000.

[4] Partition coefficient (n-octanol-water) high performance liquid chromatography (HPLC) method, OECD Guidelines for the Testing of Chemicals, vol. 117, 2004.

[5] Standard Test Method for Determining a Sorption Constant (Koc) for an Organic Chemical in Soil and Sediment, ASTM Designation E1195-01 2001.

[6] D. Mackay, Multimedia Environmental Models; The Fugacity Approach, $2^{\text {nd }}$ Edition, CRC Press, 2001, p. 96

E. A. Aziz was born in Johor, Malaysia in 1979. She received the B.Eng degree of civil engineering from National University of Malaysia. He was graduated with honors in 2001 and later finished his M.Eng degree in civil engineering (environmental management) in 2005. Currently, he is working with University Malaysia Pahang as a lecturer. Her research interest is in the environmental fate and transport process of organic compounds in environmental compartments.

W. A. Wan Omar was born in Kelantan, Malaysia in 1988. She received B.Eng degree of civil engineering from University Malaysia Pahang. She was graduated with honors in 2012. She is currently working as a research assisstant and at the same time undergoing her master education in Universiti Malaysia Pahang. Her research interest is in environmental management.

N. A. Zainodin was born in Kelantan, Malaysia in 1988. She received the B.Eng degree of civil engineering from University Malaysia Pahang and was graduated with honors in 2012. She is currently working as a research assisstant and at the same time undergoing her master education in Universiti Malaysia Pahang. Her research interest is in fate and transport process of organic compounds in environments. 